First Peoples Child \& Family Review

A Journal on Innovation and Best Practices in Aboriginal Child Welfare Administration,

Research, Policy \& Practice

\title{
Special Issue: Adolescent development, mental health, and promising research directions for Aboriginal youth
}

\section{Christine Wekerle}

Volume 3, Number 2, 2007

Special Issue: Adolescent development, mental health, and promising research directions for Aboriginal youth

URI: https://id.erudit.org/iderudit/1069456ar

DOI: https://doi.org/10.7202/1069456ar

See table of contents

Publisher(s)

First Nations Child and Family Caring Society of Canada

ISSN

1708-489X (print)

2293-6610 (digital)

Explore this journal

Cite this document

Wekerle, C. (2007). Special Issue: Adolescent development, mental health, and promising research directions for Aboriginal youth. First Peoples Child \&

Family Review, 3(2), 5-7. https://doi.org/10.7202/1069456ar 


\title{
Guest Editorial
}

\section{Special Issue: Adolescent development, mental health, and promising research directions for Aboriginal youth}

\author{
Chris Wekerle \\ Associate Professor, Education, Psychology and Psychiatry \\ Faculty of Education, The University of Western Ontario
}

\section{Introduction to this Special Issue}

Like Nature, research is a slow, steady, consistent process of growth. Research involves uncovering what exists. It also involves creating knowledge to understand natural development and testing out whether there is a good explanatory fit. With the issue of child maltreatment broadly, research has shown that there are multiple causes as to why it occurs - it can be an overload of parenting stress, a mismatch in parental personality with child personality, a misunderstanding of child capacity and reasonable expectations, ineffective sanctions for not maltreating and ineffective reward mechanisms for healthful, child-rearing. For Aboriginal populations, the causation web broadens to the level of resources available to the child, family, and community, as well as the mechanism by which such resources are obtainable in a proactive, preventative orientation. With various types of intrusions into the Aboriginal life, the challenges are to create the evidence base to understand the particular issues for Aboriginal youth, the best-fit models to conceptualize the process mechanisms, and the manner in which to intervene in process and show a demonstrated improvement in target outcome, as well as a demonstrated lack of harm. It is in the careful preliminary investigation that the most efficient and ethical models can be conducted. This involves all steps of deciding what to look at, at what stage of development, who the relevant stakeholders are, how to measure the impact of research, what are the necessary safety nets and, ultimately, how to move forward from knowledge gained. The preliminary stages of looking at existing evidence to craft the research question and the pilot phase of a research project are perhaps the most time-consuming, but most cost-beneficial elements of a longer-term vision of individual, family, and community health.

In this special section, we look at the developmental stage of adolescence and the key areas of child maltreatment history, current trauma experiences, and ways of relating. In any relationship, there are at least two interactants. There are a set of behaviours related to the self (e.g., self-harm, capacity for forming positive attachments to significant others, accepting violence towards self). There a set of behaviours related to the other (e.g., others are generally helpful, others are violent, others will listen to opinions). The self and other behaviours are variables to measure, but they are also part of even entering into a research study. One has to believe that one has a contribution to make, and that the research team will faithfully summarize the contributions of the group to show the range of behaviours, as well as the central tendencies. To engage in research is to believe that there is meaningful experience to convey, that others know how to capture these experiences, and that there is a promise of doing something helpful about the new information. Once youth have entered into a research project, ethics demand that the youth is not over-burdened and that 
the information is not ignored. Child maltreatment is a harsh experience for the youth to consider, as well as a hard experience for service providers to deal with as its effects reverberate throughout lifespan. Workers in communities are given the task of providing service to maltreated youth in the developmental level that they are at, and in dealing with the developmental tasks that are being addressed, as well as provide a liaison to the community for understanding and valuing youth mental health. If maltreatment occurred earlier in childhood, there may be a tendency to not see a youth's current adjustment difficulties through the lens of traumatization. When the population itself has undergone intrusions and traumatizations, there may be unique interactive or cumulative effects for the traumatized youth. One of the robust lifespan effects of maltreatment is alterations in the ability to keep positive emotions in the forefront and effectively cope and regulate negative emotions. Another consistent effect is in acting out, either sexually or aggressively. A main undercurrent is that maltreatment is fundamentally a relationship disruption and, therefore, involves such features as betrayal, power abuse, silencing, and an orientation towards surviving rather than thriving. All forms of maltreatment involve injury or the failure to protect from injury and so self-injury may become acceptable in terms of under-achieving, under-celebrating accomplishments, self-medication, and self-annihilation. The fight/flight instinct can becomes skewed in relationships that are vulnerable to swings of intensity of involvement and disengagement, attention and rejection, approach and avoidance, disorganization, confusion, and indecision. Functioning in close relationships affect all other spheres, such that a violent dynamic presents a challenge for a youth not unlearn what to do and re-learn or newly learn what not to do. These types of shifts represent significant resource investment to youth at a critical juncture of development, on that bridge between childhood dependence and adulthood independence.

It is a researchable question as to whether youth mental health treatment equals child abuse prevention. If a youth is supported to address their conduct, mood, and personal safety and self-care challenges, will the youth be more likely to select healthful, non-violent partners? Would youth who learn to seek-help and actively address mental health issues be more likely to become actively involved, positive parents and be more likely to seek-help when their parenting begins to falter? Since community standards informs priorities for research, both short-term and long-term learning goals need to be identified. Building the database further helps to refine priorities and sets an agenda for research funding advocacy and community support.

The goal of this special section is to begin to entertain the process and the data for forming youthrelevant research questions. The importance of adolescence is first highlighted. Attending to critical, difficult issues like self-harm, suicidal ideation, and range and level of reported maltreatment is presented in two articles on child protective services populations. These articles set the stage for the context of adolescent development and critical clinical issues to consider. The final two articles are fortunate to have been specifically conducted with First Nations youth and speak to the possible utility of brief intervention for substance use, and the utility of considering mental health alongside resiliency factors. These projects will continue to provide important evidence for action-planning in considering, for example, whether posttraumatic stress disorder symptomatology is a key feature underlying more observable problem behaviours of youth. Such theory-based research serves to direct attention to what would be the most efficient intervention target to yield the greatest level or range of positive outcomes for youth. Finally, we have a commentary by Doreen Stevens who has the unique position of being simultaneously part of the Mi'kmaq reserve community, a youth counselor based in education, a student of research in obtaining a graduate degree, as well as a co-investigator on one of the research projects.

Another addiction, among Aboriginal youth, that is rarely addressed in the literature, is that attributable to smoking. McKennitt's article points outs that the smoking rate among Aboriginal youth in Canada is two times higher than their non-Aboriginal counterparts. His observations indicate that prevention strategies need to be more holistic and adhere to the spiritual, mental, emotional and physical aspects as well as utilize the involvement of Aboriginal health professionals and should include more involved consultation with youth themselves in developing tobacco-use prevention programs.

The last three articles also focus on various social issues impacting Aboriginal youth involving housing, attachment issues and the continued process of assimilation faced by many Aboriginal youth involved 
with child welfare. For instance, the issue of youth previously involved with child welfare and housing and homelessness was explored jointly by Brown, Knol, Prevost-Derbecker and Andrushko, who note that Youth who have had child welfare involvement continue to experience the high rates of family poverty and housing challenges faced by their parents, and are often left to struggle with the same issues themselves. Brown, et al. conclude that more resources are needed to expand community-based and community-driven housing for youth who have been involved with child welfare. Neckoway, Brownlee and Castellan's article reflects on whether attachment theories are congruent with Aboriginal parenting and the cross-culturally applicability of attachment models, especially within the context of Aboriginal families. The last article, written by Richardson and Nelson's is a commentary raising concerns about the comparisons between the residential school and child welfare systems. The authors question the appropriateness of foster care for Aboriginal children and further raises the issue of whether foster care, like residential school settings, continues to enforce assimilation on Aboriginal children. While Richardson and Nelson do not assert that individual foster parents possess the intent or the values found within residential schools, they do note that for many Aboriginal children, the outcome have often been the same. They do however, assert that every 'helping' interaction between professions and Aboriginal families needs to be helpful, restorative, educational, curative and build in accountability in our sacred work with children.

Part of research is building the expertise and capacity base that can best represent the research needs, as well as the routes to research utilization. Research can highlight where popular opinion does or does not stack up to the expressed and observed reality. As the main vehicle for science, research is one route to a truth, where it is the repetition of results in different youth populations argues for a common pathway and population-specific findings argue for unique considerations. The end-goal of research is to add to that slow, steady process of knowledge that can be of demonstrable benefit and demonstrable lack of harm. 